\title{
La adaptación del Perú ante el ascenso de China a inicios del siglo XXI: entre el pragmatismo y la aquiescencia
}

\author{
Javier Ernesto Ramírez Bullón ${ }^{* *}$
}

\begin{abstract}
RESUMEN
Esta investigación busca describir y explicar el carácter de la política exterior del Perú hacia China durante inicios del siglo XXI. Desde una perspectiva histórica centrada en el rol de factores internos, el análisis identifica los principales actores gubernamentales y no estatales que moldean la relación sino-peruana en tres dimensiones principales: política/diplomática, económica/comercial y militar/estratégica. Además, el artículo muestra cómo estos aspectos se interrelacionan entre sí para dar forma a la estructura y el proceso político detrás de la adaptación del Perú ante el ascenso de China. El estudio finaliza con una reflexión sobre los beneficios y las vulnerabilidades de mantener una aproximación pragmática con China. En ese sentido, el balance final reconoce que una de las virtudes del pragmatismo es la construcción de una política exterior flexible, capaz de diversificar alianzas con múltiples grandes potencias. Sin embargo, también advierte la necesidad de comprender cómo se construyen los intereses nacionales del Perú frente a China, pues la cercanía pragmática puede encubrir una actitud internacional aquiescente.
\end{abstract}

Palabras clave: política exterior, Perú, China, diplomacia, seguridad, economía, alineamiento, aquiescencia.

\footnotetext{
Esta investigación fue desarrollada dentro del Grupo de Investigación del Orden Internacional y Órdenes Regionales (GIOR) de la Pontificia Universidad Católica del Perú. Una versión preliminar de este trabajo fue presentada como ponencia en el Congreso Anual de la Asociación de Estudios Internacionales (ISA, 2017), bajo el título The China's importance in the foreign policy of Colombia and Peru: a comparative perspective.

* Magíster en Estudios Internacionales por la Universidad de los Andes (Colombia) y licenciado en Ciencia Política y Gobierno por la Pontificia Universidad Católica del Perú. Docente en la Universidad Antonio Ruiz de Montoya e investigador en los grupos PUCP dedicados al análisis del orden internacional (GIOR) y la política exterior peruana (GIPEP). Correo electrónico: jramirezb@pucp.pe

(iD) https://orcid.org/0000-0001-5594-8307
} 
Peru's adaptation to the rise of China in the early 21 st century: Between pragmatism and acquiescence

\section{Abstract}

This paper seeks to describe and explain the character of Peruvian foreign policy towards China during the early 21 st century. From a historical perspective focused on the role of internal factors, the analysis identifies the main governmental and nonstate actors that shape the China-Peru relation in three key dimensions: political/ diplomatic, economic/ commercial, and military/strategic. Furthermore, shows how these aspects interrelate each other to shape the structure and the political process behind the adaptation of Peru to the rise of China. The study ends with some final thoughts on the benefits and vulnerabilities of maintaining a pragmatic approach to China. In this sense, the findings recognizes that one of the virtues of pragmatism is the construction of a flexible foreign policy, capable of diversify alliances with multiple great powers. However, the analysis also warns of the need to understand how the national interests of Peru are constructed vis-à-vis China, since the pragmatic proximity can hide an acquiescent international attitude.

Keywords: Foreign policy, Peru, China, diplomacy, security, economy, alignment, acquiescence.

\section{Introducción}

En la actualidad, China está aumentando su presencia en América Latina en áreas que exceden el plano económico. Por ejemplo, durante la crisis sanitaria ocasionada por la COVID-19 ha sido evidente que la potencia asiática se perfila como un proveedor importante de vacunas para los países latinoamericanos. A primera vista, este hecho muestra que China está siendo reconocida por la región como una potencia tecnológica de vanguardia. Por otro lado, el acercamiento que está asumiendo en algunos países sudamericanos, durante la pandemia, no necesariamente consiste en un acuerdo de cooperación desinteresado. En realidad, el análisis de algunos casos - tales como Brasil, Colombia, Perú y Venezuela - muestra que China coopera de manera diferenciada según criterios políticos como el mejoramiento de su prestigio o la cercanía ideológica entre tomadores de decisión (Guerra Molina, Badillo Sarmiento, y Ramírez Bullón, 2021).

Pese a que China tiene una interacción compleja y diversa con América Latina y el resto del mundo (Alcalde Cardoza, 2019), la mayor parte de la literatura académica tiende a centrarse en su influencia económica. Por un lado, algunos estudios destacan 
los beneficios obtenidos por los países latinoamericanos en términos de su acceso al mercado chino, el incremento de sus flujos comerciales y la atracción de inversiones (Barcena et al., 2011; Wise, 2016). Por otro lado, también se reconocen externalidades y desventajas tales como la desindustrialización y el fortalecimiento de una estructura económica primario exportadora (Bolinaga y Slipak, 2015; Lobato, 2013; Sevares, 2011). Aunque existen puntos de disenso respecto a cuán beneficiosa es la proyección económica china en el largo plazo, queda claro que su auge exige una adaptación asertiva desde los países latinoamericanos para aprovechar oportunidades y mitigar posibles daños.

Otras investigaciones han buscado entender el protagonismo de China en la región desde una arista política en diferentes escalas (Pastrana Buelvas y Gehring, 2017). Desde un enfoque sistémico, algunos académicos señalan que la aproximación de China en la región está delimitada (y a la vez motivada) por la competencia geoestratégica que lleva a cabo con Estados Unidos (Ellis, 2013). Desde un enfoque subregional, otros estudios observan que los países de la Alianza del Pacífico (Colombia, Chile, México y Perú) tienen visiones comunes de seguridad internacional y política comercial con Estados Unidos que podrían limitar su acercamiento con China (Ramírez Bullón, Pérez Jiménez y Badillo 2021).

Entre la literatura académica que analiza la política exterior de China en América Latina, el Perú es uno de los casos que menor atención ha recibido. Existen algunos trabajos seminales que brindan luces sobre aspectos como la negociación del acuerdo de libre comercio y los beneficios obtenidos del acercamiento económico y comercial (Chan, 2019; Mendez, Alcalde y Alden, 2019; Novak Talavera, 2012; Zanabria, 2015). Sin embargo, hay grandes vacíos sobre cómo se han desarrollado las relaciones políticas y de seguridad en paralelo al creciente rol económico del país asiático. Es decir, los análisis de política exterior suelen omitir el caso peruano y cuando realmente lo abordan son proclives a analizarlo desde una óptica economicista.

En general, los estudios de política exterior que examinan el caso peruano suelen replicar las perspectivas teóricas y metodológicas usadas para estudiar la relación entre China y América Latina. Esto puede ser un problema en la medida que se pierda de vista el carácter múltiple y no compartimentado de la realidad política internacional. En efecto, la aproximación de China en la región tiene articulaciones entre sus diferentes elementos en materia de seguridad, política y cooperación económica (Novak y Namihas, 2017).

Por lo tanto, esta investigación tiene como objetivo principal identificar las causas y consecuencias del acercamiento de Perú hacia China desde una perspectiva multidimensional. En ese sentido, el artículo analiza la adaptación del Perú frente a China en 
tres aspectos: económico-comercial, político-diplomático y militar-estratégico (este último aspecto entendido como cooperación en seguridad). Sin desmerecer la importancia del análisis sistémico, nos enfocaremos en examinar los factores internos que, dentro de cada dimensión, determinan la política exterior peruana hacia China. De esta manera, se podrán identificar actores y comportamientos que funcionan como variables explicativas del tipo de asociación, sea esta una de carácter estratégica, pragmática o aquiescente.

Esta investigación sigue una perspectiva teórica ecléctica que recoge nociones del análisis de la política exterior desarrollado por Russell y Tokatlian (2013). Además, aplica un análisis histórico basado en información documental como método para reconstruir la evolución de las relaciones políticas, económicas y militares desde el punto de vista peruano. La reconstrucción del proceso histórico, en cada dimensión de la política exterior, se realiza al seguir las acciones y declaraciones de los principales actores gubernamentales involucrados en la política externa. Al finalizar el estudio, se hace una evaluación sobre cómo la configuración de fuerzas políticas internas determina el tipo de relación que despliega el Perú hacia China.

A modo de justificación, sostenemos que se ha investigado poco sobre cómo los países latinoamericanos, y en particular el Perú, están formulando su política exterior frente al ascenso chino. La ausencia de investigación al respecto dificulta comprender en qué medida la relación con China replica antiguos patrones de autonomía, dependencia o aquiescencia. Es que, de modo general, la literatura no suele examinar cómo se diferencia el ejercicio de política exterior desde potencias menores o intermedias (Van Klaveren, 2014, p. 97). Ante este vacío explicativo, consideramos que el ascenso de China abre la posibilidad de discutir las formas de adaptación ante grandes potencias desde países menos poderosos. De hecho, solo bajo un análisis semejante es posible reflexionar sobre lo que pueden hacer los países periféricos para aprovechar a su favor los cambios del orden internacional y negociar con las grandes potencias.

La ausencia de una reflexión teórica en los análisis de política exterior puede tener repercusiones negativas para la identificación de vulnerabilidades estratégicas y la ponderación de costos y beneficios derivados de la asociación con China. Si no se reflexiona sobre cuáles son los intereses de los países latinoamericanos frente al gigante asiático es posible invisibilizar la agencia de los países menos poderosos. Los estudios que retratan a América Latina como un terreno de disputa geopolítica entre China y Estados Unidos muestran con elocuencia esta visión en la cual los intereses de los países latinoamericanos son puestos en segundo plano en favor de mostrar a la región como un espacio de ocupación pasivo (Cesarín, 2008; Nolte, 2013; Paz, 2012). 
Finalmente, la propuesta metodológica, aunque exploratoria y de carácter descriptiva, busca servir como punto de partida para investigaciones que atiendan la interrelación entre diversos factores internos de la política exterior peruana. Esta mirada holística asume que en la práctica los tomadores de decisión se ubican en un contexto con realidades superpuestas y negocian intereses provenientes de diversos sectores en competencia dentro del Estado y fuera de él.

\section{Aproximación teórica y metodológica}

Un primer problema conceptual que afronta esta investigación consiste en esbozar una noción amplia de política exterior adaptada a la realidad latinoamericana y peruana. Es común que los análisis de política exterior asuman la premisa realista a través de la cual los Estados interactúan con otros bajo presiones sistémicas o domésticas que los impulsan a buscar mayor poder en el sistema internacional (Breuning, 2007). A diferencia de dichos casos, en la política latinoamericana el interés nacional no siempre responde a la búsqueda constante de mayor poder o seguridad en el mundo, sino a una adaptación menos ambiciosa que simplemente busca aprovechar grandes tendencias globales al mismo tiempo que procura defenderse de amenazas externas (Alvarez et al., 2020).

También es menester destacar que la autonomía de política exterior se ve cuestionada en entornos políticos como la que experimenta el Perú. La imagen de una política exterior con altos grados de autonomía institucional puede ser cuestionada al situarse en el contexto político peruano. En este espacio, los vaivenes del régimen político (Vidarte, 2019), la penetración de grupos de interés en el Estado (Ramírez Bullón, 2018) o la politización de los fenómenos internacionales en la sociedad civil y los medios (Ramírez Bullón y Espinoza Vásquez, 2019), pueden cuestionar abruptamente las ideas y comportamientos que direccionan la proyección internacional del Perú. En otras palabras, los actores de la política interna, en este caso, tienen un rol protagónico en la toma de decisiones de política exterior e interactúan en un medio altamente incierto y ágil.

Por lo anterior, es importante reconocer que la política exterior peruana está fuertemente intervenida por actores no gubernamentales que penetran la definición del interés estatal. Tal como Van Klaveren (2014) argumentaba, el estudio de los actores no gubernamentales ha permitido superar el planteamiento tradicional que denominaba erróneamente al Estado como un actor unitario e indivisible en el sistema internacional. De hecho es común que los tomadores de decisión elaboren la política exterior considerando cómo sus acciones afectan a la política interna (Breuning, 2007, p. 116). Entonces, definimos como política exterior a la adaptación que 
realiza el Estado ante el medio internacional con el propósito de satisfacer un interés nacional que es construido y disputado en el escenario político nacional con otros actores no gubernamentales.

Luego de desarrollar un par de matices sobre el concepto de política exterior es necesario precisar qué actores de la política interna analizaremos. A continuación, se presentan dichos elementos con base en las reflexiones de Van Klaveren (2014) y los esquemas analíticos propuestos por Rourke (2007).

\section{Tabla 1. Actores intervinientes de la política exterior}

\begin{tabular}{|c|c|c|}
\hline Actor & Descripción & Recursos de poder \\
\hline \multirow[b]{2}{*}{$\begin{array}{l}\text { Jefes de gobierno y } \\
\text { ejecutivos políticos }\end{array}$} & Presidente, primer ministro o premier & \multirow{2}{*}{$\begin{array}{l}\text { Poder formal otorgado por ley o cons- } \\
\text { titución (es decir, comandante en jefe } \\
\text { de las fuerzas armadas de su país). } \\
\text { Poder informal: prestigio y liderazgo. }\end{array}$} \\
\hline & $\begin{array}{l}\text { Ministros de Relaciones Exteriores } \\
\text { (Secretaría de Estado) y ministros de } \\
\text { Defensa }\end{array}$ & \\
\hline \multirow{2}{*}{ Burocracias } & Personal gubernamental de carrera & \multirow{2}{*}{$\begin{array}{l}\text { Procesan información, elaboran reco- } \\
\text { mendaciones, implementan políticas. }\end{array}$} \\
\hline & Designados políticos o funcionarios & \\
\hline \multirow[b]{2}{*}{ Legislaturas } & $\begin{array}{llll}\begin{array}{l}\text { Legislaturas } \\
\text { democráticos }\end{array} & \text { en sistemas no }\end{array}$ & $\begin{array}{l}\text { Influencia baja. Sellan las decisiones de } \\
\text { los líderes políticos. }\end{array}$ \\
\hline & Legislaturas en países democráticos & $\begin{array}{l}\text { Amplias pero limitadas según el diseño } \\
\text { institucional y el tipo de relaciones } \\
\text { ejecutivo-legislativo. }\end{array}$ \\
\hline \multirow{4}{*}{$\begin{array}{l}\text { Grupos de interés } \\
\text { / Asociaciones } \\
\text { privadas }\end{array}$} & $\begin{array}{l}\text { Grupos culturales (religiosos, étnicos } \\
\text { o raciales), }\end{array}$ & \multirow{4}{*}{$\begin{array}{l}\text { Se consideraba que eran menos activos } \\
\text { e influyentes en la política exterior que } \\
\text { en las cuestiones de política nacional, } \\
\text { pues su influencia es informal. Sin } \\
\text { embargo, su repercusión puede ser } \\
\text { determinante de acuerdo con la situa- } \\
\text { ción de la política interna y la debi- } \\
\text { lidad del Estado. }\end{array}$} \\
\hline & Grupos o gremios económicos & \\
\hline & $\begin{array}{l}\text { Grupos de interés conformados en } \\
\text { torno a un tema específico }\end{array}$ & \\
\hline & Grupos de interés transnacionales & \\
\hline \multirow{3}{*}{$\begin{array}{l}\text { La sociedad/ } \\
\text { Público }\end{array}$} & $\begin{array}{l}\text { Opinión pública en gobiernos } \\
\text { autoritarios }\end{array}$ & Actor marginal. \\
\hline & Opinión pública en democracias & $\begin{array}{l}\text { En ocasiones, juega un papel clave, } \\
\text { especialmente en temas internos } \\
\text { (comercio). }\end{array}$ \\
\hline & Electores en democracias & $\begin{array}{l}\text { A veces tienen la opción de elegir } \\
\text { candidatos para puestos de liderazgo } \\
\text { nacional que tienen diferentes obje- } \\
\text { tivos y prioridades de política exterior } \\
\text { particulares. }\end{array}$ \\
\hline
\end{tabular}

Fuente: Rourke (2007, pp. 81-90). Elaboración propia. 
Para analizar la interacción de estos actores es útil recurrir a los conceptos de estructura y proceso de decisión elaborados por Russell (1990). Según esta mirada, la estructura de politica exterior hace referencia a los actores gubernamentales domésticos que tienen la capacidad de comprometer los recursos de poder del país. Supone, entonces, el núcleo convencional de toma de decisiones, el cual se distingue por su legitimidad política y legal. Por otra parte, el proceso de decisión es la dinámica política en la que diversos actores gubernamentales y no gubernamentales interactúan para crear la proyección internacional del país.

Es decir, la estructura de política exterior es compuesta por quienes tienen la «última decisión» dentro del Estado (Hermann y Hagan citados en Russell 1990, p. 256). En este caso, bajo la Constitución peruana vigente, el centro de la estructura decisoria en materia de política exterior es el presidente de la República y, en segundo orden, el Canciller y el Ministerio de Relaciones Exteriores, en tanto tienen un papel operativo y propositivo. Por otro lado, en la práctica, la dinámica política peruana también empodera a otros actores del Estado según factores como la cercanía política o capacidad técnica que los hagan visibles para la estructura decisoria.

La idea de un proceso de decisión que no se centra únicamente en lo que hacen los actores más importantes del Estado permite reconocer el papel de otros actores que de manera coyuntural pueden tener interés e influencia en la política exterior. Por ejemplo, en materia de negociación de tratados de libre comercio el Ministerio de Comercio Exterior y Turismo (MINCETUR) tiene un rol protagónico y algo similar sucede con el Ministerio de Defensa (MINDEF) cuando se negocia la adquisición de equipamiento militar. Asimismo, más allá de los actores estatales, también es importante estudiar a los grupos de interés económico e incluso a la sociedad civil como actores incidentales del proceso decisorio. Esto se debe a que en Perú la estructura decisoria es altamente susceptible de la esfera pública por la alta incertidumbre social y política, así como por la permeabilidad de las instituciones estatales frente a la influencia de grupos de interés privados (Pedraglio Mendoza y Mormontoy Atauchi, 2019).

Con el fin de ordenar las diversas dinámicas involucradas en la interacción sinoperuana es posible dividir analíticamente la política exterior según sus áreas temáticas más importantes. Según el planteamiento de Russell (1990), estas dimensiones son: económica-comercial, político-diplomática y militar-estratégica. A través de esta delimitación se busca explorar cómo en cada una de las dimensiones de la política exterior peruana existen actores y patrones comunes durante la aproximación con China. Por ello, en cada sección se indican los antecedentes históricos más resaltantes y los actores estatales o no gubernamentales protagónicos. Esta aproximación sirve para hacer un seguimiento a cómo se compone la estructura decisoria y permitirá 
determinar las características del proceso de decisión de política interna que define (u opaca) el interés nacional del Perú en su proyección hacia China.

Cabe indicar que el periodo temporal del análisis se centrará en lo sucedido a inicios del siglo XXI hasta el año 2016, porque tras la llegada al poder de Trump en EE. UU. se intensificó la competencia geopolítica entre China y Estados Unidos. Ello inició un contexto diferente de política exterior china en la región, fenómeno sobre el cual todavía existe una incipiente literatura científica (Bernal-Meza y Xing, 2020; Stallings ,2020). Además, a partir de 2016 también ocurrió un cambio de gobierno importante en Perú que inició una fuerte incertidumbre en la política externa sobre la cual no existe suficiente información documental para reconstruir su estructura y proceso.

\section{La dimensión política y diplomática}

El primer antecedente de relaciones diplomáticas entre ambos países se dio en 1874, cuando la joven república peruana y el imperio chino firmaron en Tiensin un «Tratado de amistad, comercio y navegación» (Novak y Namihas, 2016, p. 37) ${ }^{1}$. Este acercamiento formal sucedió incluso después del primer contacto directo entre las sociedades de ambos países, pues en 1849 comenzó la llegada de casi cien mil chinos al Perú (Aquino Rodríguez, 2013, p. 8)². Durante las décadas siguientes, la integración cultural de los chinos en Perú tuvo trascendencia a nivel social pero no en materia de política exterior. Por ejemplo, siguiendo la tendencia de la mayoría de los países latinoamericanos, en 1949 Perú optó por reconocer a Taiwán, desconociendo al régimen de Mao Tse-Tung.

Por otro lado, en 1971, motivado por una visión de mayor autonomía en la política exterior, el gobierno militar de Juan Velasco Alvarado decidió reconocer a la República Popular China, la Unión Soviética y Cuba (Alcalde Cardoza y Romero Sommer, 2014). Con esta decisión, Perú pasó a ser el segundo Estado sudamericano en reconocer oficialmente a la RPC, después de Chile, y el tercero de toda América Latina, después de Cuba (Samanamud, 2014, p. 246). Desde este acercamiento formal, Perú mantiene la política de «Una sola China» ${ }^{3}$.

\footnotetext{
1 La primera aproximación de Perú hacia China puede rastrearse incluso durante tiempos coloniales, cuando en el siglo XVI la corona española importaba productos chinos que llegaban a Perú (García-Corrochano y Tang, 2011, p. 34).

2 La migración china al Perú fue vista como fuente de fuerza laboral barata destinada a la explotación de recursos naturales y la construcción de ferrocarriles. De esta manera, inicialmente reemplazó el trabajo de esclavos que habían sido liberados en 1845 (Aquino Rodríguez, 2013, p. 8).

3 Por su parte, China ha respaldado la tesis peruana sobre la soberanía marítima de 200 millas (Berríos, 2013, p. 136).
} 
Aunque el acercamiento del gobierno militar peruano con China fue originado por intereses económicos ${ }^{4}$, fue posible una profundización de los lazos diplomáticos debido a su colaboración en el grupo de países no alineados. A diferencia de los Estados sudamericanos que apoyaban a EE. UU. durante su contienda con la URSS, Perú optó por distanciarse de una dinámica bipolar. En este sentido, la política exterior peruana tuvo coincidencias con la estrategia geopolítica de China al menos durante parte de la Guerra Fría (Samanamud, 2014, p. 247).

Tras el fin del gobierno de Velasco (1975) y la profundización de problemas internos — como el terrorismo (1981-1990) y la grave crisis económica (1987-1990)— Perú experimentó un acelerado retroceso en el ímpetu autonomista de su política exterior. Ello tuvo incidencia en el estancamiento de la relación diplomática de Perú con Asia, hasta que en 1991 el recién electo Alberto Fujimori decidió hacer giras por esa región, al realizar la primera visita oficial de un presidente peruano a China (Aquino Rodríguez, 2013).

En la década de 1990, Perú experimentaba grandes transformaciones políticas y económicas que lo obligaron a redefinir sus relaciones diplomáticas. A finales de 1992, poco después de cerrar el congreso usando la fuerza, Fujimori decidió suprimir 117 cargos diplomáticos, lo cual perturbó la profesionalidad tradicional de la cancillería peruana (La República, 9 de octubre de 2011). Como consecuencia, Fujimori tuvo mayor injerencia política sobre la diplomacia peruana, subordinando a esta institución de acuerdo con su visión particular del mundo, la cual brindaba una mayor prioridad a la región Asia-Pacífico.

Fujimori, a diferencia de otros presidentes peruanos, buscó acercarse con mayor firmeza a algunos países asiáticos, entre ellos China. Ello no solo se debía a la cercanía cultural que le otorgaba su ascendencia japonesa, sino que también existía en Perú un estereotipo social favorable sobre los denominados «tigres asiáticos»". Por lo tanto, en la opinión pública peruana se mantenía la expectativa de que, durante el gobierno de Fujimori, el país experimentara un mayor acercamiento a los poderes emergentes de Asia. Además, es importante considerar que, tras el golpe de Estado de 1992,

\footnotetext{
4 Según Bruce St John (1999), en ese año, Perú restableció relaciones con la RPC motivado por la búsqueda de un mercado para productos no tradicionales, como la harina de pescado (1999, p. 193).

5 El imaginario peruano sobre los «tigres asiáticos» existía un par de décadas antes de Fujimori y se centraba en los éxitos económicos de dichos países, tal como lo expresa la revista política Caretas en 1996: «el encanto en este lado de América por los países de la Cuenca del Pacífico se remonta a comienzos de la década del 70, cuando comenzaban a llegar noticias impresionantes sobre ciertos «milagros» económicos en Corea del Sur, Taiwán, Hong Kong y, más recientemente en Singapur y Malasia» (Caretas, 21 de noviembre de 1996).
} 
Fujimori buscó nuevos socios internacionales poco críticos de su comportamiento no democrático, como lo fueron algunos países asiáticos ${ }^{6}$.

Un actor doméstico que impulsó el acercamiento de Perú con Asia fue el empresariado. Por ejemplo, una semana antes de que Fujimori llegara a Japón, se celebró una conferencia entre empresarios peruanos y japoneses, en la cual participaron representantes del Estado, como el ministro de Industria peruano quien, aludiendo a los inversionistas japoneses, declaró: «tenemos economías complementarias: nosotros somos productores de materias primas y ellos tienen tecnología y la capacidad de realizar inversiones de capital» (Caretas, 6 de mayo de 1993). De esta forma, se puede observar una creciente penetración de perspectivas empresariales en la dirección de la diplomacia peruana, fomentando la búsqueda de mercados como interés nacional por encima de la búsqueda de mayor autonomía.

Debido a sus nuevas prioridades, la diplomacia peruana logró que el Perú sea miembro de algunos foros multilaterales que lo acercaron a China: en 1990 ingresó al Pacific Business Economic Council (PBEC) y en 1991 al Pacific Economic Cooperation Council (PECC). En adición, en 1998, Perú pudo ser parte del Asia Pacific Economic Cooperation Forum (APEC) (Berríos, 2013, p. 137). Además, en este escenario de profundo cambio en la política exterior peruana, Fujimori incluyó a China dentro de sus giras a Asia y al final de su gobierno de diez años visitó al gigante asiático cuatro veces ${ }^{7}$ (Aquino Rodríguez, 2013).

A partir del antecedente histórico mencionado, se puede afirmar que la cercanía de Perú hacia China cuenta con interesantes elementos políticos y sociales que lo distinguen de los demás países latinoamericanos. Esta particularidad no cambió pese a las nuevas transformaciones que vivió Perú durante inicios del siglo XXI, con el regreso de la democracia y la reestructuración del aparato diplomático. Como muestra de ello, en 2004, Perú otorgó estatus de economía de mercado a China y en 2005 el presidente Toledo visitó oficialmente China (Aquino Rodríguez, 2013, p. 10).

El hecho más importante de las actuales relaciones diplomáticas de Perú y China se produjo en 2008 cuando el presidente chino Hu Jintao y su homólogo peruano, Alan García establecieron una «alianza estratégica» que en 2009 desembocó en el Tratado de Libre Comercio (TLC) Perú-China (Sanborn y Yong, 2013, p. 7). A partir de

\footnotetext{
6 Un hecho que ejemplifica esta convergencia respecto a la democracia entre algunos países asiáticos y el régimen de Fujimori se dio cuando el primer ministro de Malasia, durante visita oficial a Perú, realizó una apología del autogolpe de 1992 (Caretas, 21 de noviembre de 1996).

7 Por su parte, en 1995 Li Peng, primer ministro de la RPC, fue el primer jefe de Estado chino que hizo una visita oficial al Perú.
} 
entonces, China ganó mayor importancia para Perú, al punto de considerarlo un socio estratégico integral.

Tabla 2. Principales aspectos de la alianza estratégica entre Perú y China

\begin{tabular}{|c|c|}
\hline Aspectos & Mecanismos \\
\hline \multirow{2}{*}{ Fortalecer las relaciones políticas } & $\begin{array}{l}\text { Contacto de alto nivel a través de consultas políticas y comi- } \\
\text { siones conjuntas }\end{array}$ \\
\hline & $\begin{array}{l}\text { Intercambios entre agencias gubernamentales, legislaturas, } \\
\text { partidos políticos y sociedad civil }\end{array}$ \\
\hline \multirow{2}{*}{ Ampliar la cooperación económica } & Leyes económicas y comerciales \\
\hline & Cooperación entre empresas de ambos países \\
\hline $\begin{array}{l}\text { Promover la integración y el } \\
\text { desarrollo }\end{array}$ & $\begin{array}{l}\text { Intercambio de conocimiento mutuo en áreas clave (educa- } \\
\text { ción, cultura, etc.) }\end{array}$ \\
\hline \multirow{2}{*}{$\begin{array}{l}\text { Mantener una estrecha cooperación a } \\
\text { nivel multilateral }\end{array}$} & $\begin{array}{l}\text { Coordinar posiciones sobre temas internacionales y regio- } \\
\text { nales de interés común. }\end{array}$ \\
\hline & $\begin{array}{l}\text { Colaborar con organizaciones internacionales y regionales } \\
\text { (OMC, ONU, APEC, Focalae, etc.) }\end{array}$ \\
\hline
\end{tabular}

Adaptado de Novak y Namihas, 2016, pp. 45-46.

También se puede destacar que el presidente peruano, Humala, viajó a China en visita oficial en 2013, al ser uno de los primeros presidentes latinoamericanos en reunirse con el recién elegido presidente Xi Jinping ${ }^{8}$ (Aquino Rodríguez, 2013, p. 10). En aquella ocasión,

Los dos mandatarios celebraron su «alianza estratégica integral» con la firma de once nuevos acuerdos bilaterales orientados a optimizar su infraestructura comercial, fortalecer la cooperación en agricultura e infraestructura así como en minerales, incrementar la cooperación para el desarrollo social y profundizar sus vínculos más allá de lo comercial. (Sanborn y Yong, 2013, p. 7)

Con el renovado compromiso de una asociación estratégica, en 2014 llegó a Lima el presidente de la Asamblea Popular Nacional de la China, Zhang Dejiang, y fue recibido por el presidente Humala. En esta oportunidad, se dio un énfasis al

\footnotetext{
8 Cabe destacar que durante esa visita se abrió el Centro de Estudios Peruanos en la Universidad Normal de Hebei, el primero de su tipo en China (Aquino Rodríguez, 2013, p. 17).
} 
acercamiento social por medio de la inauguración del «Centro de la Amistad Peruano China» (Novak y Namihas, 2016, p. 49).

Posteriormente, el presidente Pedro Pablo Kuczynski (PPK) no tardó en hacer explícito la creciente importancia que tiene China para el Perú. Tan solo dos meses después de asumir la presidencia PPK eligió a China como destino de su primer viaje oficial al extranjero. Al contar por qué decidió realizar ese viaje, PPK declaró a los medios peruanos que «hay mucha tecnología, educación e inversión que traer al Perú», además precisó: «no estamos buscando créditos [...], lo que estamos buscando es inversión y cooperación» (El Comercio, 12 de setiembre de 2016). Al finalizar este viaje, el presidente peruano calificó la visita como exitosa y compartió el agrado de las autoridades chinas al saber que China fue su primer destino (Diario Oficial El Peruano, 18 de setiembre de 2016) ${ }^{9}$.

En noviembre de 2016, dos meses después de la visita de PPK, el presidente Xi Jinping participó en la APEC realizada en Lima, Perú y extendió su permanencia con el fin de celebrar nuevos acuerdos y reafirmar su compromiso con el libre mercado, aludiendo así al temor de una nueva etapa proteccionista impulsada por Donald Trump (El Comercio, 10 de febrero de 2016). En aquella oportunidad, la visita del presidente chino reforzó nuevamente los vínculos diplomáticos y además tuvo gran visibilidad mediática al recibir una condecoración especial por parte del Congreso peruano (La República, 21 de noviembre de 2016b). Cabe destacar que dicha ceremonia, en la que paradójicamente un congreso democrático condecoró al líder del partido comunista chino, solo fue criticada parcialmente por algunos congresistas y no opacó el ambiente festivo con el que se recibió al presidente chino (La República, 21 de noviembre 2016a).

Finalmente, para finalizar un año de intenso acercamiento entre Perú y China, el ministro de Asuntos Exteriores chino, Wang Yi, realizó una gira oficial a Sudamérica que incluyó a Perú. En el encuentro se analizaron los asuntos regionales e internacionales de interés común (El Comercio, 30 de setiembre de 2016).

\footnotetext{
9 Cabe indicar que algunos medios de comunicación favorables a China comentaron este acercamiento, pero resaltando que "las autoridades peruanas se han comprometido a solucionar en el corto y mediano plazo" algunos problemas que enfrentó la inversión china en la minería peruana (China hoy, 2016).
} 
Tabla 3. Visitas oficiales de presidentes peruanos a la RPC

\begin{tabular}{cc}
\hline Ańo & Presidente \\
\hline 1991 & Alberto Fujimori \\
1994 & Alberto Fujimori* \\
1995 & Alberto Fujimori \\
2005 & Alejandro Toledo \\
2008 & Alan García \\
2013 & Ollanta Humala \\
2016 & Pedro Pablo Kuczynski \\
\hline
\end{tabular}

*Visitó China dos veces ese año. Fuente: Elaboración propia.

En síntesis, luego de la declaración de asociación estratégica la importancia de China para la política exterior peruana aumentó considerablemente. Aunque los propósitos de la cooperación sean mayoritariamente económicos, el acercamiento diplomático fue indispensable, especialmente el dirigido por las cabezas de gobierno. Es así que todos los presidentes peruanos del siglo XXI (hasta 2016) —Toledo, García, Humala, Kuczynski - priorizaron la relación con China al realizar visitas oficiales y con la firma de acuerdos de cooperación en diversas áreas.

Tras identificar a los actores y procesos domésticos que han llevado al acercamiento de Perú hacia China se puede destacar que la diplomacia se encuentra fuertemente direccionada por el presidente y la burocracia comercial, esta última representada por el Ministerio de Comercio Exterior y Turismo (MINCETUR). Además, los últimos presidentes peruanos han hecho explícito el interés en la inversión y el comercio chino. Por otro lado, pese a que una relación diplomática incluye diversas áreas de cooperación, existe un fuerte discurso económico asociado a la política exterior en la cobertura mediática y el pensamiento social peruano. Esta convergencia entre los presidentes, la burocracia y parte de la sociedad civil muestra una convergencia en las percepciones relativamente optimistas respecto al «ascenso pacífico» de China.

Sin embargo, es preciso reconocer que detrás de los acuerdos existentes que vinculan a Perú y China no hay mucho avanzado en cuanto a una visión estratégica de política exterior. Tal como lo señala Zanabria (2015), al carecer de una visión integral hacia China, «no se ha diseńado una agenda integradora, de corto, mediano y largo plazo» (Zanabria, 2015, p. 94).

Por último, según Novak y Namihas (2016), la relación entre Perú y China cambió en el nuevo siglo debido a la apertura económica del Perú en los años 1990 y la nueva política comercial de 2001 (Novak y Namihas, 2016, p. 39). De aquí se desprende 
la importancia de analizar la dimensión económica para entender cómo se proyecta Perú hacia China. Esta dimensión será explorada en la siguiente sección, al dar especial atención a la coyuntura del TLC con China.

\section{Dimensión económica-comercial}

Aunque Fujimori fue electo bajo la promesa de no aplicar una reforma liberal, realizó la más drástica apertura del comercio y la inversión extranjera en un Estado latinoamericano (Alcalde Cardoza, 1997). Como consecuencia, la política económica de Perú cambió a favor del libre comercio y se incrementó paulatinamente el intercambio comercial con países como China. De esta forma, las exportaciones peruanas a la RPC pasaron de 140 a 676 millones de dólares, en el intervalo de 1993 a 2003; mientras que, en el mismo periodo, las importaciones desde ese país aumentaron de 90 a 646 millones de dólares (Aquino Rodríguez, 2013, p. 9).

El comercio entre Perú y China mantiene casi los mismos rasgos desde finales del siglo XX. En primer lugar, para China la minería representa el sector económico más dinámico del Perú, debido a su riqueza mineral ${ }^{10} \mathrm{y}$ a su posición geográfica, ya que la salida natural al Pacífico facilita el transporte de este tipo de recursos (Samanamud, 2014, p. 248). Además, ya que Perú es el principal productor mundial de harina de pescado y China el principal consumidor, más del $50 \%$ de la producción peruana de dicho alimento es exportado hacia China (Fairlie, 2015, p. 74). De otro lado, las exportaciones chinas a Perú tienen alta diversificación, pues incluyen productos con valor agregado, como maquinaria y dispositivos de computación. Pese a ello, la importancia de Perú para China es marginal, existiendo un interés comercial mucho menor (Samanamud, 2014, p. 250).

Al observar los flujos de inversión extranjera directa (IED), China ocupa un lugar menos importante para Perú. Por ejemplo, hasta junio de 2015 la IED acumulada de Perú era de 24146 millones de dólares y de este total solo 208,1 millones provenían de la RPC (Zanabria, 2015, p. 91). Por otro lado, debe reconocerse que la inversión china suele realizarse a través de empresas domiciliadas en otros países, además ha seguido creciendo, sobre todo en el sector minero ${ }^{11}$ (Zanabria, 2015, p. 91). Según esta tendencia, en 2016, autoridades chinas comunicaron que la inversión de su país en Perú había superado los 14000 millones de dólares (Andina, 26 de agosto de 2016).

\footnotetext{
${ }^{10}$ Los minerales que Perú le exporta a China son cobre, plomo, zinc, hierro, molibdeno, plata, aluminio y acero (Fairlie Reinoso, 2010, p. 14).

${ }^{11}$ Se debe precisar que «more than 95 percent of Chinese investment in Chile and Peru has been of a «resourceseeking» nature and concentrated almost solely in mining» (Wise, 2016, p. 85).
} 
En general, estos datos muestran que la forma en que Perú se ha acercado económicamente a la RPC es básicamente a través de la exportación de minerales y alimento, a cambio de manufacturas e inversión en minería. En este escenario, desde 2006, Perú optó por negociar un Tratado de Libre Comercio (TLC) con China, «motivados por el objetivo de atraer IED china hacia inversiones de eficiencia y búsqueda de mercado, a diferencia de la actual avalancha de inversiones entrantes en búsqueda de recursos limitadas a la extracción de minerales» (Wise, 2016, p. 89).

El TLC de Perú y China, se suscribió en el año 2009 y entró en vigor en el año 2010. Este acuerdo comprende comercio de bienes, servicios e inversiones, además contiene un capítulo de Cooperación Aduanera y un Memorándum de Entendimiento sobre Cooperación Laboral y Social (Fairlie, 2015, p. 72). Por lo tanto, a partir de 2010, la inversión china en Perú se protege como proveniente de un país desarrollado. Esto se da a pesar de que no se incluyeron adendas sobre temas laborales, propiedad intelectual y tampoco requisitos medioambientales que impliquen la adopción de elevados estándares $^{12}$ (Fairlie, 2015, p. 73).

El inicio de las negociaciones fue una propuesta peruana, encabezada por la ministra de MINCETUR (Mercedes Aráoz), institución que en aquel momento ya tenía una alta profesionalización y experiencia al impulsar el TLC con EE. UU. (Chan, 2019). La experiencia ganada en acuerdos anteriores fue muy importante porque la profesionalización de la burocracia comercial en Perú era indispensable para negociar un TLC con la RPC (Wise, 2012, p. 143). Esto evidencia la importancia de la tecnocracia comercial (Mincetur) y algunos altos ejecutivos de la política exterior (Aráoz).

$\mathrm{Al}$ mismo tiempo, llama la atención la poca importancia que tienen las evaluaciones políticas o la menor participación del Ministerio de Relaciones Exteriores en el proceso decisorio que permitió el TLC con China. Esta particularidad resalta ya que un TLC genera consecuencias políticas en el ámbito doméstico y externo que deben ser previstas con mayor cuidado; por ejemplo, cuando afectan a grupos de interés internos o procesos de integración regional (Büthe y Milner, 2008; Grossman y Helpman, 1993).

La decisión de negociar un TLC con China aparece como parte de una política comercial dirigida por las cabezas de gobierno (presidente García) y «ejecutivos políticos» del área comercial (Aráoz). Si bien durante este proceso la participación popular parece mínima, es importante resaltar que el gobierno intentó destacar los beneficios del acuerdo ante la opinión pública y los stakeholders involucrados (Chan,

\footnotetext{
12 Sobre el mismo acuerdo también existe una lectura académica que resalta los logros del Perú. Como lo indica Wise (2016), «Peru was quite proactive in reducing tariffs on 99 percent of its exports to China, 83.5 percent of which entered the Chinese market duty free at theoutset of the agreement» (Wise, 2016, p. 96).
} 
2019). El mensaje más recurrente, difundido en publicidad televisiva y conversaciones con la prensa, fue que el mercado chino representaba un gran tamaño y tendría la capacidad de absorber una parte relevante de productos de exportación, especialmente alimentos procesados (Samanamud, 2014, p. 250). De esta forma, el mensaje enviado a la sociedad relacionaba al acuerdo con el crecimiento económico, el incremento de las exportaciones y la integración del país a la economía mundial. Asimismo, la tecnocracia comercial y los académicos liberales difundían como ideafuerza que a través del nuevo TLC el Perú "podría transformarse en un hub de transporte y servicios para el comercio transpacífico» (Hoadley y Yang, 2007).

Entre los actores favorables al TLC con China, se ubicaban grupos de interés como los exportadores de materias primas y alimentos procesados. Estos productores «han presionado [...] para exportar más productos no tradicionales y de mayor valor agregado al mercado chino" (Wise, 2016, p. 89). En un tercer orden de importancia, también se pueden ubicar a algunos medios de comunicación favorables al acuerdo comercial, quienes debido a su cercanía ideológica con el libre comercio enmarcaron las noticias relacionadas al tema como un posible éxito económico (El Comercio, 28 de abril de 2009b). El periódico El Comercio fue parte de ese comportamiento mediático con titulares como "Con el TLC con China no solo creceremos en minería y energía» (El Comercio, 28 de abril de 2009a).

Desde una posición poco influyente en el proceso decisorio, la sociedad peruana no mostró gran conmoción ante la negociación y firma del TLC, lo cual puede haber favorecido el desenlace de una firma y ratificación sin muchos cuestionamientos. Ello puede deberse al poco seguimiento de temas políticos de la opinión pública, pero también a su conformidad con la política de libre comercio impulsada por los gobiernos del siglo XXI (Ramírez Bullón, 2018). Cabe indicar que, a diferencia de otras sociedades sudamericanas, un acercamiento gubernamental hacia China es menos politizado, probablemente debido al factor de la alta inmigración china en Perú, el cual podría funcionar como un proceso social intermediario que mitiga el sentimiento nacionalista y proteccionista de la sociedad ${ }^{13}$.

Pese a la rápida negociación y firma del acuerdo con China, en comparación al que firmó Perú con EE. UU., también existieron algunos grupos de interés críticos. Por ejemplo, los sectores relacionados a la fabricación de textiles ${ }^{14}$, calzado y metalmecánica se veían alarmados por la posibilidad de que los productos chinos entren al

\footnotetext{
${ }^{13}$ Este aspecto, sin embargo, merece ser examinado a profundidad en una investigación que atienda la interrelación entre la cultura política y política exterior.

${ }^{14}$ Durante una visita de Jack Ma (millonario creador de Alibaba.com) y la ministra de Producción peruana a un conocido centro comercial de textiles (Gamarra), se produjo una protesta contra el TLC con China (La República, 2008).
} 
mercado peruano (González Vigil, 2012, p. 355; Ministerio de Comercio Exterior y Turismo (MINCETUR) 2007) ${ }^{15}$. Entre estos actores, la industria de la confección de Perú, que emplea a aproximadamente 100000 personas, podía ser la más afectada (Collyns, 2008; Gestión, 2010). Estos grupos de interés se mostraron especialmente descontentos porque «en algunos casos se beneficiaron del crédito subsidiado canalizado por el gobierno peruano» (Gonzalez-Vicente, 2012, p. 108). En segundo orden, entre los grupos críticos también se encontraban algunos sectores de la sociedad civil como medios de comunicación de tendencia progresista (La República, 20 de noviembre de 2008) y académicos (Torres, 2010).

Más allá de la coyuntura alrededor del acuerdo de libre comercio, la actual presencia económica de China en Perú se encuentra parcialmente cuestionada. Tal situación se debe al estilo chino de hacer negocios y a la experiencia de algunas compañías mineras que han traído efectos medioambientales nefastos para el Perú. Por ejemplo, en Cajamarca, una de las regiones más pobres del Perú, se desarrollaron violentas protestas contra la contaminación del suministro de agua local por parte de empresas mineras estadounidenses y chinas (Sanborn y Torres, 2009). Otro caso emblemático es el de la empresa china Shougang, que opera mina de hierro más grande del país (Samanamud, 2014, p. 248). En este último caso, la trayectoria de la compañía Shougang incluso ha sido comparada con las empresas chinas en África (Malamud, 2012, p. 3).

El interés comercial de Perú en China se encuentra explicitado bilateralmente a través del TLC y de modo multilateral a través de la Alianza del Pacífico (2011). La Alianza del Pacífico fue publicitada como un modelo exitoso porque en su momento fue innovador plantear una proyección comercial conjunta hacia las economías de Asia-Pacífico (Bernal-Meza, 2015). En este sentido, el bloque buscaba brindar mayor capacidad de negociación a sus países miembro para contrarrestar la «reprimarización» del comercio con China (Malamud, 2012, p. 4) ${ }^{16}$. Sin embargo, desde el Perú esa posibilidad aparece lejana debido a que el rol institucionalizado por el Perú frente a China parece el de una potencia primario-exportadora frente a un centro manufacturero.

Otro caso que ejemplifica la percepción economicista de China entre quienes conforman la estructura decisoria del Perú es el proyecto de un «corredor bioceá-

\footnotetext{
${ }^{15}$ Cabe indicar que González Vigil también identifica a países vecinos que intentaban socavar las negociaciones de Perú y China, ya que también buscan ser «hub en la zona del Pacífico Suramericano y/o de liderar los negocios con el Asia-Pacífico» (González Vigil, 2012, p. 355).

$16 \mathrm{Al}$ respecto, se ha planteado que los países que conforman la Alianza puedan generar productos competitivos al establecer una política industrial común (Samanamud, 2014, pp. 257-258). Ello, sin embargo, parece poco probable debido a la identidad primario-exportadora de Perú, Colombia y Chile.
} 
nico» que uniría a Brasil y Perú para facilitar el intercambio comercial de China. Este proyecto fue planteado en la visita oficial del presidente Humala en China (2014) y se llegó a firmar un memorando de entendimiento para crear el primer grupo de trabajo en torno al ferrocarril que uniría el océano Pacífico con el Atlántico (Gestión, 2014) ${ }^{17}$. En 2015 la importancia de este proyecto fue renovada durante la visita del primer ministro Li Keqiang a Perú cuando se suscribió nuevamente un memorándum de entendimiento sobre el proyecto ferroviario (Novak y Namihas, 2016, p. 49).

Pese al entusiasmo inicial, Perú perdió interés en el ferrocarril debido a la complejidad de la infraestructura, el costo medioambiental—al atravesar la Amazonía - y los beneficios limitados que podría recibir de esta obra ${ }^{18}$. Además, no se establecieron compromisos para la transferencia de tecnología, empleo, ni revisión de políticas comerciales. Por último, también existe una consecuencia geopolítica poco favorable para el Perú, tal como lo señala Adins (2016): «La Ferrovía Transcontinental BrasilPerú (Fetab) solo convertirá al Perú en un país nexo entre dos potencias, repitiendo así de cierta manera la lógica ferroviaria «mina-puerto», propia del siglo XIX, sin ningún beneficio para la sociedad como tal» (p. 87).

Resumidamente, la interpretación que tiene el Perú sobre China tiene una fuerte connotación economicista debido a procesos decisorios como la liberalización de la economía y la creciente influencia de la burocracia comercial peruana en la proyección internacional del país. La apertura económica que experimentó el Perú en los años noventa es el antecedente más importante en este proceso, ya que estableció nuevas prioridades en materia de política exterior económica que ayudaron al acercamiento con China. De esta forma, China es visible para Perú como un mercado, antes que como una potencia retadora del sistema internacional.

Además, desde la formación de una burocracia comercial especializada (Mincetur en 2002) y la firma del TLC (2009), durante la última década China ha escalado su posición económica en Perú hasta convertirse en su primer socio comercial desde 2012 (La República, 23 de enero de 2012). Ello ha generado beneficios para los grupos económicos que exportan a China, principalmente mineros y agroexportadores, así como ha permitido el ingreso de bienes de consumo baratos para la sociedad. Desde otro punto de vista, el ingreso de productos chinos a bajo costo está generando insatisfacción en grupos de interés peruanos, como el debilitado sector textil quienes acusan a China de la desindustrialización del país.

\footnotetext{
${ }^{17}$ En este encuentro oficial, también se selló un acuerdo de cooperación económica por el que China donaría 11,5 millones de dólares a Perú (Gestión, 2014).

${ }^{18} \mathrm{El}$ inicio de este proyecto estaba previsto para el 22 de mayo de 2016 y ha sido propuesto de manera indefinida por el Perú (Adins, 2016, p. 87).
} 
Si bien el intercambio comercial con China tiende a ser favorable para el Perú, entre ambos países se mantiene una relación centro-periferia, al ser las materias primas casi el $92 \%$ de todo lo que se exporta al gigante asiático ${ }^{19}$ (Zanabria, 2015, p. 91). Probablemente esta situación motivó que durante el encuentro ente los presidentes Kuczynski y Xi Jinping, se firmara un convenio que buscó «optimizar» el TLC (El Comercio, 21 de noviembre de 2016). El hecho de que esta «optimización» se plantee sin un debate público previo evidencia que los jefes de gobierno y ejecutivos políticos son los actores más influyentes en el proceso decisorio de política exterior hacia China y gozan de alta autonomía al decidir la estrategia de inserción internacional del Perú.

Algunos actores no gubernamentales, como los medios de comunicación y la opinión pública, no tuvieron un rol homogéneo y varían su apoyo al acercamiento con China según su apoyo al libre comercio. Por ejemplo, en el caso de la TLC con la RPC, mientras que algunos académicos y medios denunciaban la política comercial China como «opaca $»^{20}$, otros celebraron el acuerdo como una nueva etapa de oportunidades y crecimiento (Torres, 2010, p. 37). Cabe indicar que las decisiones tomadas para afianzar las relaciones económicas con China están respaldadas por grupos de interés privados interesados en la exportación de minerales y alimentos procesados.

\section{Dimensión militar/estratégica}

A diferencia de los avances en la cooperación económica y política entre Perú y China, existen pocos acercamientos en el ámbito militar y de seguridad. Antes del siglo XXI, no existen antecedentes importantes de una cooperación en materia militar entre el ejército peruano y chino. Sin embargo, se puede destacar que Perú muestra algunas condiciones que favorecen su interés en cooperación militar con China, a diferencia de otros aliados de Estados Unidos en Sudamérica.

El factor más destacable es que tradicionalmente el ejército peruano también tiene fuentes de armamento no americanas. Ello se puede rastrear desde el gobierno militar de Velasco (1968-1975), cuando se compró importante material bélico a la Unión Soviética, rompiendo así la dependencia del suministro estadounidense (Alcalde Cardoza y Romero Sommer, 2014, p. 17). Desde entonces, Perú ha mostrado mayor autonomía al establecer lazos militares con diferentes potencias. Por ejemplo, ha establecido acuerdos de cooperación con países como Brasil (2012), Rusia (2014) y

\footnotetext{
${ }^{19}$ Actualmente, China compra a Perú la mitad de su exportación de cobre, casi toda la producción de hierro y más del 70\% de harina de pescado (Zanabria, 2015, p. 91).

${ }^{20}$ Esta caracterización se basa en las prácticas desleales de China como el dumping o subsidios que buscan proteger a sus productores nacionales y los bienes que ellos exportan (Samanamud, 2014, p. 253).
} 
Corea del Sur (2015) (El Comercio, 14 de febrero de 2012, 20 de abril de 2015; La República, 8 de noviembre de 2014).

Luego de finalizar la lucha contra el terrorismo interno de la década de 1990, los presidentes peruanos otorgaron menor atención al aspecto militar. En un contexto de pocas amenazas internas y externas ${ }^{21}$, Perú no tiene como prioridad la construcción de una amplia política exterior de seguridad. Así, durante inicios del siglo XXI, el interés de cooperación internacional del Ministerio de Defensa (MINDEF) se centra en la modernización de sus fuerzas armadas, entre otros objetivos. En este escenario, China es considerada como un proveedor potencial de nuevo armamento, aunque todavía con una importancia menor frente a países como Rusia y Corea del Sur.

Los primeros acercamientos relevantes entre China y Perú, en materia de seguridad, se realizaron a partir del año 2007, cuando se firmaron acuerdos que permitieron a la RPC participar directamente en el sistema peruano de adquisiciones militares (Ellis, 2012, p. 51).Un par de años más tarde, en coincidencia con la firma del TLC, una flotilla naval china ${ }^{22}$ realizó una gira por los puertos del Pacífico sudamericano, haciendo escalas en Valparaíso, Chile; Callao, Perú y en Guayaquil, Ecuador (Ellis, 2012, p. 48).

Junto al incremento de la cooperación militar, en 2009 surge un intento de colocar a China como nuevo proveedor de armamento para Perú. En este año, un grupo de cinco tanques MBT-2000 de la RPC, fue aceptado para ser evaluados por el ejército peruano, lo cual acercaba a Perú como el primer país de América Latina en comprar vehículos blindados de China (Ellis, 2012, p. 50). La institución que gestionó este proceso fue el Ministerio de Defensa peruano, pero el presidente García y su ministro de Defensa Rafael Rey tuvieron un rol protagónico. Tras un desfile militar que exhibió a los tanques chinos ante los medios y la opinión pública, el ministro de Defensa Rey manifestó que «Perú tiene la firme intención de comprar tanques de fabricación china dentro del plan para recuperar la capacidad disuasiva de las Fuerzas Armadas» (El Comercio, 8 de diciembre de 2009).

\footnotetext{
${ }^{21}$ El Ministerio de Defensa peruano identifica las siguientes amenazas externas: doctrinas de seguridad incompatibles con la vigencia del derecho internacional, escasez de recursos naturales y redes internacionales de terrorismo, narcotráfico y delincuencia. Por su lado, las amenazas internas del Perú son las siguientes: grupos terroristas y subversivos, grupos que promueven la violencia social y desborde popular, delincuencia organizada, tráfico de drogas, corrupción y depredación del medio ambiente (Ministerio de Defensa del Perú [MINDEF] 2005, p. 63).

22 Esta comitiva incluyó al destructor Shijiazhuang y el buque de aprovisionamiento Hongzehu. Según Ellis (2012), «tales visitas benefician a la Armada del EPL [Ejército popular de liberación], ayudándola a identificar los requerimientos para el uso de puertos latinoamericanos por sus barcos en el futuro a efectos de mantenimiento, reabastecimiento u otros fines (Ellis, 2012, p. 48).
} 
Pese a los cuestionamientos de carácter técnico y la desconfianza de los medios y la sociedad en el armamento chino, el gobierno de García parecía tener una decisión sólida. Incluso a finales de 2010 el ministro de defensa peruano reiteró que «la compra del tanque chino es una decisión política» y añadió que era una decisión respaldada por los institutos armados del Perú23 (La República, 1 de julio de 2011). Poco tiempo después, aparecieron rumores de postergación en la compra que incluso denunciaban la injerencia de Estados Unidos como un obstáculo; sin embargo, el ministro Rey desmintió toda sospecha y volvió a declarar que «los blindados chinos [...] siguen siendo para el Perú la mejor alternativa técnica dentro del mercado» (El Comercio, 15 de abril de 2010).

En paralelo a la negociación de la compra de tanques chinos, en 2010 aumentaron los contactos entre militares de alto nivel entre ambos países, incluyendo visitas de ministros de Defensa, jefes del Estado Mayor y otros oficiales superiores chinos y peruanos $^{24}$ (Ellis, 2012, p. 45). Al finalizar 2010 también se realizaron ejercicios conjuntos de carácter humanitario, al incluir un ejercicio entre 39 militares chinos y 50 peruanos en el cual se brindaron servicios médicos a una población vulnerable de Lima (Ellis, 2012, p. 48).

En este periodo, signado por la compra de los tanques chinos, Perú recibió la primera donación importante de equipo humanitario militar por parte de la RPC. Esta primera donación consistió en un hospital de campaña y otros equipos valorizados en 300 millones de dólares (Ellis, 2012, p. 50). Además, en enero de 2011, se suscribieron acuerdos de cooperación militar como el «Primer protocolo complementario al convenio sobre asistencia militar», por el cual el Perú recibió una donación de vehículos militares que tenían el valor de seis millones de yuanes (Novak y Namihas, 2016, p. 46).

A pesar del firme apoyo que parecía mostrar el gobierno peruano para la compra de tanques chinos, en abril de 2011, este proceso fue cancelado. La razón técnica de este fracaso fue que los tanques incluían motores ucranianos que no tenían licencia de exportación a terceros países (Infodefensa.com, 2017). Por otro lado, la adquisición de armamento chino se había politizado en el ámbito interno y continuaban los rumores sobre la poca confiabilidad de aquellos tanques. Por ello, la compra de nuevo armamento ya no parecía contar con alta autonomía y podría haber representado un costo político para el gobierno de García.

\footnotetext{
${ }^{23}$ El Ejército peruano proyectaba incorporar al menos 120 tanques, por alrededor de 564 millones de dólares (La República, 1 de julio de 2011).

${ }^{24}$ Cabe indicar que China realizó este tipo de intercambio con otros países latinoamericanos como Venezuela, Ecuador, Chile, México, Brasil, Colombia y Bolivia (Ellis, 2012, p. 48).
} 
Finalmente, la compra de tanques chinos se canceló y el gobierno peruano afirmó que, en vez de los blindados, que costaban 4,7 millones de dólares cada uno, se gastaría el dinero en helicópteros de combate y transporte que operan en las zonas donde existe narcotráfico y remanentes de Sendero Luminoso. La RPC manifestó su desacuerdo con el cambio de decisión peruana y enviaron cartas de protesta al Ministerio de Defensa. Incluso ofertaron los cinco tanques por 19 millones de dólares, pero Perú rechazó la propuesta. Debido a un corte presupuestal, el Ejército peruano incluso tuvo problemas para devolver los tanques a China ya que no contaba con dinero ni siquiera para transportarlos al puerto del Callao (La República, 1 de julio de 2011).

A pesar de la fallida compra, Perú y China han seguido impulsando la cooperación militar. Poco tiempo después de cancelarse la compra de tanques, el vicepresidente de la comisión militar central (CMC), Xu Cihou, declaró «China espera que los dos países [Perú y la RPC] puedan hacer esfuerzos conjuntos para avanzar en la cooperación amistosa entre los dos ejércitos» (Andina, 4 de mayo de 2011). Además, con la presidencia de Humala en Perú (2011), apareció una nueva oportunidad de compra de armamento chino. En ese caso, Perú mostró interés por el lanzador múltiple de cohetes Tipo 90B, el cual, según especialistas, es una copia mejorada del BM-21 ruso que el Perú compró en la década de 1970 (La República, 26 de diciembre de 2016).

Humala concretó la compra de lanzadores en 2013 por un valor de 38,5 millones de dólares a la empresa estatal china NORINCO, la cual también fabricaba los tanques que fueron cancelados por Perú. En aquella ocasión, la compra de armas no tuvo resonancia pública y solo organismos técnicos del Ejército peruano ${ }^{25}$ se encargaron de hacer las evaluaciones. Los lanzadores chinos fueron elegidos por encima de propuestas como la de Estados Unidos (HIMARS) y la Federación Rusa (BM-30 Smerch). Incluso se preveía la compra de 3200 cohetes y 40 vehículos lanzadores de China, pero la compra se redujo a 528 cohetes (La República, 26 de diciembre de 2016). Dos años después de la compra (2015) los lanzadores fueron presentados oficialmente al público en una ceremonia con la presencia del presidente y el ministro de Defensa peruano Valakivi.

La compra de lanzadores chinos fue cuestionada en 2016, pues se ha demostrado que este armamento registra deficiencias técnicas. Incluso se ha abierto un proceso judicial a algunos militares peruanos que validaron el estado óptimo del equipo bélico, sin contar con autorización para hacerlo (La República, 26 de diciembre de 2016). Perú había dado un adelanto de 23,6 millones a la empresa china Norinco sin verificar el buen funcionamiento de su armamento.

25 Comité Especial Técnico Operativo (CETO), pero la parte técnica fue responsabilidad del Servicio de Material de Guerra del Ejército (SMGE). 
Perú recibió nuevas donaciones de China y continuó firmando nuevos acuerdos de cooperación militar con la RPC hasta inicios del gobierno de PPK (Infodefensa.com 2016). Por ejemplo, en 2016, China se comprometió a donar equipos y materiales para las fuerzas armadas peruanas que están valorizadas en más de siete millones de dólares (Andina, 16 de diciembre de 2016). Estas últimas aproximaciones denotan el interés de China en posicionarse como un proveedor de armas en Perú, sin embargo, hasta el momento la política exterior peruana no parece responder con el mismo entusiasmo a este acercamiento.

Esto podría deberse a la mala percepción de las armas chinas que alarma a la opinión pública y los medios, lo cual genera que los gobiernos peruanos teman bajar su popularidad acercándose militarmente a China. Por otro lado, existen importantes razones técnicas y actores externos que pueden estar involucrados, ya que Perú ha tenido una mejor relación de cooperación en seguridad con países como Rusia. En este escenario, la experiencia de la compra fallida de tanques chinos (2011) y los lanzadores de cohetes dańados (2016) dificultaron que China aumente su importancia para la política exterior peruana en el ámbito militar.

\section{Reflexiones finales}

Luego de explorar la aproximación de Perú hacia China en sus tres dimensiones principales es posible sintetizar cuáles son sus principales rasgos y qué móviles están detrás de su acercamiento multidimensional hacia China. A continuación, a modo de recapitulación, se ubican los actores identificados en el proceso decisorio de la política exterior peruana en una matriz que los diferencia según su nivel de interés e influencia en la política exterior de Perú hacia China.

La exploración histórica realizada nos indica que la política exterior peruana hacia China está condicionada por un interés comercial pragmático. Es más, desde que China se convirtió en uno de los compradores más importantes de los commodities peruanos se impulsaron las demás dimensiones de la relación con la RPC. La alta demanda china por materias llegó a beneficiar económicamente a las élites económicas peruanas, lo cual ayudó a generar un contexto de política interna favorable para el acercamiento con China. A inicios del siglo XXI, esta realidad resonaba con la constitución hegemónica del libre comercio en Perú (Ramírez Bullón, 2018), el cual funcionó como un marco interpretativo a través de la cual los tomadores de decisión priorizaron las lógicas económicas por encima de otros criterios en su evaluación sobre los riesgos y oportunidades del acercamiento con China. 
Figura 1. Actores domésticos que intervienen en la política exterior de Perú hacia China

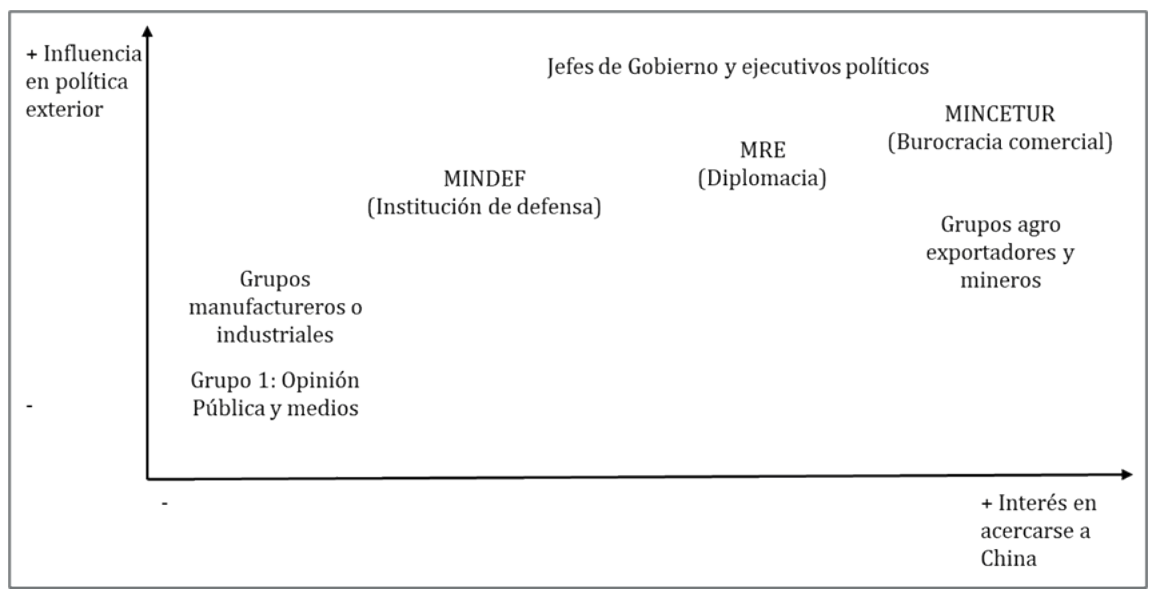

En consecuencia, la RPC fue vista principalmente como un mercado deseable antes que como una potencia retadora del orden global o como un Estado comunista. En la medida que prevaleció una óptica economicista, los acuerdos de cooperación firmados con China fueron interpretados como un acercamiento pragmático hacia una economía estratégica.

Otra característica importante es la baja influencia que tienen los actores no gubernamentales en la formulación de la política exterior peruana. Actores como las ONG, la opinión pública y la academia tienden a ser desestimados en el proceso de toma de decisiones frente a China. En contraposición, los grupos de interés más poderosos al interior de la sociedad ejercen una influencia destacada. Ello se refleja, por ejemplo, en el respaldo de los grupos mineros y agroexportadores al TLC con China.

Por ende, afirmamos que Perú ha mantenido un enfoque económico-pragmático en la formulación de su política exterior hacia China. Si bien, Perú aún considera a Estados Unidos como un aliado de primer orden, esto no le impide desarrollar vínculos con otros países que pueden ser catalogados como contestatarios al poder americano. Esta actitud se pone en evidencia en aspectos como el número de visitas oficiales que han hecho los presidentes peruanos a China, así como en los vínculos militares que ha intentado establecer con China. Es un rasgo que se ha mantenido incluso cuando el presidente Pedro Pablo Kuczynski tenía nacionalidad estadounidense, pero consideró a China país como el socio más importante de Perú ${ }^{26}$. A modo

\footnotetext{
${ }^{26}$ Esto se demuestra en que la primera visita internacional realizada por Kuczynski al inicio de su mandato fue a China.
} 
de síntesis, desagregamos los componentes que configuran el carácter pragmático que encontramos en la política exterior peruana hacia China.

Tabla 4. Factores que determinan el pragmatismo de Perú frente a China

\begin{tabular}{|c|c|}
\hline Factor & Descripción \\
\hline Modelo económico interno & Mercado libre. Desarrollo hacia afuera. \\
\hline Política comercial imperante & Libre comercio y exportación de materias primas \\
\hline $\begin{array}{l}\text { Posición geopolítica y desarrollo } \\
\text { portuario }\end{array}$ & $\begin{array}{l}\text { Economías asiáticas identificadas como principales } \\
\text { socios comerciales }\end{array}$ \\
\hline $\begin{array}{l}\text { Estructura de las instituciones de } \\
\text { política exterior }\end{array}$ & $\begin{array}{l}\text { Mayor influencia de las instituciones comerciales } \\
\text { en la política exterior }\end{array}$ \\
\hline $\begin{array}{l}\text { Estrategia de seguridad y relación } \\
\text { con el poder hegemónico }\end{array}$ & $\begin{array}{l}\text { Mayor autonomía en la compra de armamento de } \\
\text { fuentes no americanas }\end{array}$ \\
\hline Jerarquía de grupos de interés & $\begin{array}{l}\text { Alto nivel de organización e influencia de los } \\
\text { grupos agroexportadores, mineros }\end{array}$ \\
\hline $\begin{array}{l}\text { La ideología imperante en los } \\
\text { responsables de la política exterior }\end{array}$ & Pragmatismo económico \\
\hline $\begin{array}{l}\text { Imágenes sociales y proximidad } \\
\text { cultural }\end{array}$ & $\begin{array}{l}\text { Mayor conocimiento de China a través de la inte- } \\
\text { gración cultural de los inmigrantes }\end{array}$ \\
\hline
\end{tabular}

Para finalizar, es pertinente hacer un balance crítico sobre la forma en que Perú decidió relacionarse con China a inicios del siglo XXI. Perú experimentó un acelerado acercamiento multidimensional hacia China. Sin embargo, ello es motivado por intereses económicos de corto alcance que limitan la construcción de una política exterior basada en intereses nacionales de gran envergadura. Si bien el acercamiento a China puede ser beneficioso para el Perú, es imprescindible un previo reconocimiento de los intereses que busca en China desde un enfoque holístico. Sin ese reconocimiento sobre lo que Perú desea obtener de China y cuáles son sus intereses no negociables es probable que el alineamiento pragmático pueda devenir en una actitud aquiescente o, en el peor de los casos, en una subordinación no explícita de la política exterior peruana. Esto podría suceder sin que China desee explícitamente replicar patrones de dominación, sino por falta de concertación de actores internos peruanos frente a amenazas externas o porque la estructura decisoria de la política exterior haya internalizado una actitud pasiva e introvertida en su relacionamiento con el mundo. 
Asimismo, los actores gubernamentales que deciden cómo se adapta Perú al ascenso de China necesitan aumentar los lazos intersectoriales dentro del Estado. Ello se podría lograr mejorando la comunicación de las instituciones de comercio exterior, diplomacia y defensa en la búsqueda de una estrategia conjunta. Por otra parte, asuntos económicos como el TLC o la llegada de multinacionales chinas tienen alta influencia en el ámbito político doméstico, por lo cual es necesario que estas interacciones sean evaluadas considerando los puntos de vista de grupos de interés afectados.

Con todo, existen aristas desde las cuales es necesario realizar mayor investigación para determinar un balance holístico sobre cuan beneficioso es el acercamiento de Perú frente a China. La experiencia de empresas como Shoughan y Chinalco en el Perú muestran cómo los chinos pueden pasar por alto estándares ambientales. Una experiencia similar se replica frente al asunto del corredor bioceánico, en el cual se asume que a Perú le conviene ser un país intermediario. Estas realidades complejas exigen la creación de espacios de reflexión activa sobre cómo aprovechar el ascenso chino y adaptarse ante él desde los recursos de poder disponibles para el Perú.

Finalmente es necesario enriquecer el debate público sobre la inserción internacional de Perú en Asia desde la sociedad y la academia. Por lo tanto, proponemos las siguientes preguntas subsidiarias para futuras investigaciones: ¿qué oportunidades y desafíos en términos materiales e ideológicos representa el ascenso de China para el Perú? ¿en qué medida la relación con China replica patrones de dependencia económica y política ante grandes potencias? Y, finalmente, ¿qué implicancias muestra el caso peruano para la discusión sobre las formas de adaptación de países periféricos ante el cambio del orden internacional?

\section{Referencias bibliográficas}

Adins Vanbiervliet, S. (2016). La Ferrovía Transcontinental Brasil-Perú: contexto, efectos económicos y geopolítica. En J. Caillaux, F. Novak y M. Ruiz (Eds.), Las relaciones de China con América Latina y el Ferrocarril Bioceánico Brasil-Perú (pp. 61-94). Sociedad Peruana de Derecho Ambiental (SPDA) e Instituto de Estudios Internacionales (IDEI).

Alcalde Cardoza, J. (2019). La proyección global y regional de China. En Á. Méndez, J. Alcalde Cardoza, C. Alden y A. Guerra-Barón (Eds.), La conexión china en la Politica Exterior del Perú en el siglo XXI (pp. 25-52). The London School of Economics Global South Unit (LSE-GSU LSE IDEAS), Instituto de Estudios Internacionales (IDEI) y Escuela de Gobierno de la Pontificia Universidad Católica del Perú (PUCP).

Alcalde Cardoza, J. (1997). La liberalización de la inversión extranjera directa en América Latina: un breve enfoque comparativo de Brasil, Chile, Perú y el Grupo Andino. Apuntes: Revista de Ciencias Sociales, O(41), 3-33. https:/doi.org/10.21678/ apuntes.41.302. 
Alcalde Cardoza, J. y Romero Sommer, G. (2014). Alineamiento y desafío: la politica exterior peruana en los gobiernos de Odría y Velasco. Escuela de Gobierno y Políticas Públicas de la Pontificia Universidad Católica del Perú.

Alvarez, S. T., Devés, E., Aldana, C., Simonoff, A. C., Sánchez Mugica, A., Cervo, A. L., Figueroa Jiménez, A., Serbín, A., Domínguez Ávila, C. F. y Escudé, C. (2020). Problemáticas internacionales y mundiales desde el pensamiento latinoamericano. Ariadnaediciones.

Andina. (4 de mayo de 2011). Perú y China acuerdan impulsar cooperación en tecnología militar.

Andina. (16 de diciembre de 2016). China donará al Perú 50 millones de yuanes en equipos para Fuerzas Armadas.

Andina. (26 de agosto de 2016). China se ha convertido en el mayor socio comercial del Perú | Noticias | Agencia Andina.

Aquino Rodríguez, C. (2013). Acerca de los estudios sobre China en el Perú. Pensamiento Critico, 18(2), 007-018.

Bárcena, A., Prado, A., Rosales, O. y Pérez, R. (2011). La República Popular China y América Latina y el Caribe: Hacia una nueva fase en el vinculo económico y comercial. CEPAL.

Bernal-Meza, R. (2015). Alianza del Pacífico versus ALBA y Mercosur: entre el desafío de la convergencia y el riesgo de la fragmentación de Sudamérica. Pesquisa \& Debate, 26(47), 1-34.

Bernal-Meza, R. y Xing, L. (2020). China-Latin America Relations in the 21st Century: The Dual Complexities of Opportunities and Challenges. Springer Nature.

Berríos, R. (2013). Bridging the Pacific: Peru’s Search for Closer Economic Ties with China. En A. E. F. Jilberto y B. Hogenboom. Latin America Facing China: South-South Relations beyond the Washington Consensus. Berghahn Books.

Bolinaga, L. y Slipak, A. (2015). El Consenso de Beijing y la reprimarización productiva de America Latina: el caso argentino. Problemas del Desarrollo. Revista Latinoamericana de Economía, 46(183), 33-58.

Breuning, M. (2007). Foreign policy analysis: A comparative introduction. Palgrave Macmillan.

Bruce St John, R. (1999). La politica exterior del Perú. Asociación de Funcionarios del Servicio Diplomático del Perú.

Büthe, T. y Milner, H. V. (2008). The politics of foreign direct investment into developing countries: increasing FDI through international trade agreements? American Journal of Political Science, 52(4), 741-762.

Caretas. (6 de mayo de 1993). Cruzada oriental: ofensiva palaciega empresarial para tender puentes con el lejano Oriente.

Caretas. (21 de noviembre de 1996). El Lejanísimo Oriente: Termina gira presidencial por tres países de Asia que no están demasiado lejos.

Cesarín, S. (2008). El factor China en los nuevos equilibrios regionales. Ponencia presentada en el Seminario de FUNAG (Fundação Alexandre de Gusmão) e IPRI (Instituto de Pesquisa de Relaçóes Internacionais), China: perspectivas y desafíos. Brasilia. 
Chan, J. (2019). Los nueve años del TLC Perú-China. Su negociación y sus resultados. Agenda Internacional, 26(37), 89-117. https://doi.org/10.18800/agenda.201901.003

China hoy. (2016). La histórica visita del presidente Xi Jinping a Perú. http://www.chinatoday.mx/pol/content/2016-12/30/content_733087.htm

Diario Oficial El Peruano. (18 de setiembre de 2016). El presidente Kuczynski califica de misión exitosa visita a China.

El Comercio. (28 de abril de 2009a). Con el TLC con China no solo creceremos en minería y energía. El Comercio, abril 28.

El Comercio. (28 de abril de 2009b). El Perú y China firman hoy un TLC que complementará sus economías.

El Comercio. (8 de diciembre de 2009.) Rey: Perú está a punto de comprar tanques chinos.

El Comercio. (15 de abril de 2010). Gobierno ratifica que comprará tanques chinos.

El Comercio. (14 de febrero de 2012). Los convenios firmados entre Perú y Brasil para la cooperación en industria militar.

El Comercio. (20 de abril de 2015). Perú y Corea del Sur firmaron cinco convenios de cooperación. El Comercio. http://elcomercio.pe/economia/peru/peru-y-corea-surfirmaron-cinco-convenios-cooperacion-ollanta-humala-noticia-1805433.

El Comercio. (10 de febrero de 2016). Xi Jinping: La íntima amistad entre el Perú y China borra la lejanía. http://elcomercio.pe/politica/actualidad/ xi-jinping-sobre-peru-intima-amistad-borra-lejania-noticia-1948179.

El Comercio. (12 de setiembre de 2016). PPK sobre gira en China: 'Hay mucha inversión que traer a Perú'.

El Comercio. (30 de setiembre de 2016). Canciller de China realizará visita a Perú la próxima semana. http://elcomercio.pe/politica/gobierno/ canciller-china-realizara-visita-peru-proxima-semana-noticia-1935587.

El Comercio. (21 de noviembre de 2016). PPK y Xi Jinping acuerdan mejorar TLC entre el Perú y China. http://elcomercio.pe/politica/gobierno/ ppk-y-xi-jinping-acuerdan-optimizar-tlc-entre-peru-y-china-noticia-1948073/1.

Ellis, R. E. (2012). China-Involucramiento militar en América Latina: buena voluntad, buen negocio y posición estratégica. Air \& Space Power Journal en Español, 43-56.

Ellis, R. E. (2013). The strategic dimension of Chinese engagement with Latin America. William J. Perry Center for Hemispheric Defense Studies.

Fairlie, A. (2015). China potencia económica y comercial: una mirada desde el Perú. Agenda Internacional, 22(33), 55-80.

Fairlie Reinoso, A. (2010). Relaciones económicas Perú-China (Coyuntura). Revista del Centro Andino de Estudios Internacionales, 9, 11-35.

García-Corrochano, L. y Tang, R. (2011). Las relaciones entre el Perú y China. Instituto de Estudios Internacionales (IDEI) de la PUCP e Instituto Confucio-PUCP.

Gestión. (2014). China apoyará en construcción de conexión ferroviaria bioceánica Perú-Brasil. http://gestion.pe/empresas/ china-apoyara-construccion-conexion-ferroviaria-bioceanica-peru-brasil-2113652 
González Vigil, F. (2012). El TLC China-Perú: un testimonio desde el sector académico peruano. En C. Moneta y S. Cesarín. Tejiendo redes: Estrategias de las empresas transnacionales asiáticas en América Latina.

Gonzalez-Vicente, R. (2012). The Political Economy of Sino-Peruvian Relations: A New Dependency? Journal of Current Chinese Affairs, 41(1), 97-131.

Grossman, Gene M. y Elhanan Helpman. (1993). The politics of free trade agreements. National Bureau of Economic Research.

Guerra Molina, R.A., Badillo Sarmiento, R. y Ramírez Bullón, J.E. (2021). La competencia entre China y Estados Unidos durante la pandemia de covid-19: escenarios de adaptación para la política exterior sudamericana. En E. Vieira Posada (Ed.), La pandemia de COVID-19 y un nuevo orden mundial (pp. 155-191). Fondo Editorial-Ediciones Universidad Cooperativa de Colombia.

Hoadley, S. y Jian Yang. (2007). China's cross-regional FTA initiatives: towards comprehensive national power. Pacific Affairs, 80(2), 327-348.

Infodefensa.com. (2016). China dona 7,2 millones de dólares en equipos militares a las FFAA de Perú - Noticias Infodefensa América. Infodefensa.com. http://www.infodefensa. $\mathrm{com} /$ latam/2016/12/22/noticia-china-ministerio-defensa-siete-millones-dolaresequipos-militares.html

Infodefensa.com. (2017). Perú investiga la adquisición de los lanzadores múltiples Norinco a China. Noticias Infodefensa América. Infodefensa.com. http://www.infodefensa.com/ latam/2017/01/05/noticia-nuevamente-sistemas-armas-chinos-juicio.html

La República. (20 de noviembre de 2008). Textiles protestan por el TLC con China. larepublica.pe. http://larepublica.pe/20-11-2008/textiles-protestan-por-el-tlc-con-china).

La República. (1 de julio de 2011). No hay dinero para devolver tanques chinos MBT-2000. larepublica.pe

La República. (9 de octubre de 2011). Los embajadores y los golpes. larepublica.pe. http:// larepublica.pe/09-10-2011/los-embajadores-y-los-golpes

La República. (23 de enero de 2012). China es el primer socio comercial de Perú. larepublica. pe. http://larepublica.pe/23-01-2012/china-es-el-primer-socio-comercial-de-peru

La República. (8 de noviembre de 2014). Humala y Putin afianzan cooperación militar y nuclear. larepublica.pe. http://larepublica.pe/08-11-2014/ humala-y-putin-afianzan-cooperacion-militar-y-nuclear

La República. (21 de noviembre de 2016a). Bancada del Frente Amplio en contra de condecoración del Congreso a presidente de China. larepublica.pe. http://larepublica. pe/politica/823754-bancada-del-frente-amplio-en-contra-de-condecoracion-delcongreso-presidente-de-china

La República. (21 de noviembre de 2016b). Xi Jinping, presidente de China, fue condecorado por el Congreso. larepublica.pe

La República. (26 de diciembre de 2016). Compraron con fallas lanzador de cohetes chino que costó US\$ 38.5 millones. larepublica.pe 
Lobato, M. P. (2013). Las relaciones entre China y América Latina y el Caribe. ¿Un nuevo modelo de cooperación o una forma de neocolonialismo? América Latina en la turbulencia global: oportunidades, amenazas y desafios (pp. 79-89). Servicio de Publicaciones.

Malamud, C. (2012). La Alianza del Pacífico: un revulsivo para la integración regional en América Latina. Documento ARI 46:2012.

Méndez, Á., Alcalde, J. y Alden, C. (2019). Análisis de la Política Exterior de Perú hacia China en el siglo XXI. En Á. Méndez, J. Alcalde Cardoza, C. Alden, y A. GuerraBarón (Eds.), La conexión china en la politica exterior del Perú en el siglo XXI (pp. 25-52). The London School of Economics - Global South Unit (LSE-GSU LSE IDEAS), Instituto de Estudios Internacionales (IDEI) y Escuela de Gobierno de la Pontificia Universidad Católica del Perú (PUCP).

Ministerio de Comercio Exterior y Turismo [MINCETUR]. (2007). Peru - China Free Trade Agreement: Joint Feasibility Study.

Ministerio de Defensa del Perú [MINDEF]. (2005). Libro Blanco de la Defensa Nacional.

Nolte, D. 2013. The Dragon in the Backyard: US Visions of China's Relations toward Latin America. Papel Politico, 18(2), 587-598.

Novak, F. y Namihas, S. (2016). Las relaciones bilaterales entre el Perú y la República Popular de China (2006-2016). En J. Caillaux, F. Novak, y M. Ruiz (Eds.), Las relaciones de China con América Latina y el Ferrocarril Bioceánico Brasil-Perú (pp. 38-60). Sociedad Peruana de Derecho Ambiental (SPDA) e Instituto de Estudios Internacionales (IDEI) de la PUCP.

Novak, F. y Namihas, S. (2017). La inserción de China en ALC y el Perú. Su impacto en la relación con la UE. Instituto de Estudios Internacionales (IDEI) de la PUCP y Konrad Adenauer Stiftung.

Novak Talavera, F. (2012). Reseña GARCÍA-CORROCHANO, Luis y Rubén TANG. Las relaciones entre el Perú y China. Serie Política Exterior Peruana. Agenda Internacional, 18(29), 409-409.

Pastrana Buelvas, E. y Gehring, H. (2017). La proyección de China en América Latina y el Caribe. Editorial Pontificia Universidad Javeriana.

Paz, G. S. (2012). China, United States and Hegemonic Challenge in Latin America: An Overview and Some Lessons from Previous Instances of Hegemonic Challenge in the Region. The China Quarterly, (209), 18-34. http://dx.doi.org.ezproxybib.pucp.edu. pe:2048/10.1017/S0305741011001469

Pedraglio Mendoza, S. y Mormontoy Atauchi, E. (2019). TLC Peru-China: El papel de los Grupos de Interés Economico. Fondo Editorial de la Pontificia Universidad Católica del Perú.

Ramírez Bullón, J. E. (2018). La legitimación del libre comercio en la política exterior peruana: del TLC con Estados Unidos al surgimiento de la Alianza del Pacífico [tesis de Licenciatura en Ciencia Política y Gobierno, Pontificia Universidad Católica del Perú].

Ramírez Bullón, J. E. y Espinoza Vásquez, L. P. (2019). La prensa escrita y la política exterior peruana durante el diferendo marítimo con Chile. Fondo Editorial de la Pontificia Universidad Católica del Perú. 
Ramírez Bullón, J. E., Pérez Jiménez, A. y Badillo, R. (2021). El alineamiento en seguridad internacional de los países de la Alianza del Pacífico con Estados Unidos: una aproximación desde el realismo constructivista. Desafíos, 33(1).

Rourke, J. T. (2007). International Politics on the World Stage. McGraw-Hill Education.

Russell, R. (1990). Politica exterior y toma de decisiones en América Latina: aspectos comparativos y consideraciones teóricas. Grupo Editor Latinoamericano.

Russell, R. y Tokatlian, J.G. (2013). América Latina y su gran estrategia: entre la aquiescencia y la autonomía / Latin America and its grand strategy: between acquiescence and autonomy. Revista CIDOB d'Afers Internacionals, 157-180.

Samanamud, G. T. (2014). China en América Latina: los casos de Ecuador y Perú entre los años 2009-2012 ¿Es posible una apuesta hacia el futuro? Anuario Mexicano de Derecho Internacional, (14), 221-260.

Sanborn, C. y Torres, V. (2009). La economía china y las industrias extractivas: desafíos para el Perú. Departamento de Economía de la Universidad del Pacífico.

Sanborn, C. y Yong Manrique, A. S. (2013). Peru's economic boom and the Asian connection. Centro de Investigación de la Universidad del Pacífico.

Sevares, J. (2011). El ascenso de China: oportunidades y retos para América Latina. Nueva Sociedad, (235), 35-49.

Stallings, B. (2020). Dependency in the twenty-first century?: The political economy of ChinaLatin America relations. Cambridge University Press.

Torres, V. (2010). El TLC Perú-China: ¿Oportunidad o Amenaza? Red Peruana por una Globalización con Equidad - RedGE.

Van Klaveren, A. (2014). El análisis de la política exterior: una visión desde América Latina. Introducción a las relaciones internacionales: América Latina y la politica global, México, 96-109.

Vidarte, O. (2019). Cambios en el régimen político y su impacto en la política exterior peruana. (Vol. 1). Fondo Editorial de la PUCP.

Wise, C. (2012). The China Conundrum: Economic Development Strategies Embraced by Small States in South America. El dilema chino: estrategias de desarrollo económico emprendidas por Estados pequeños en Sudamérica, (75), 131-170.

Wise, C. 2016. Playing Both Sides of the Pacific: Latin America's Free Trade Agreements with China. Pacific Affairs, 89(1), 75-101. http://doi: 10.5509/201689175

Zanabria, L. 2015. Las relaciones entre el Perú y China. En F. Novak y J. García (Eds.), La politica exterior peruana en el siglo XXI: Agenda y propuestas. Instituto de Estudios Internacionales (IDEI) de la PUCP y Konrad Adenauer Stiftung.

Fecha de recepción: 30 de abril de 2021

Fecha de aprobación: 31 de agosto de 2021 